\title{
Conservation, Cultivation, and Commodification of Medicinal Plants in the Greater Himalayan-Tibetan Plateau
}

\author{
Sienna R. Craig and Denise M. Glover
}

This special issue of Asian Medicine: Tradition and Modernity emerges from the Seventh International Congress of the International Association for the Study of Traditional Asian Medicine (IASTAM), which was held in Thimphu, Bhutan, from 7-11 September 2009. As readers of this journal may be aware, IASTAM's unique vision aspires to bring academics and practitioners of Asian medical traditions into dialogue with each other, to promote the study and cross-cultural understanding of Asian medicines from a variety of disciplinary perspectives, and to do so in a way that honours and embraces the sometimes difficult task of reckoning the world of reflection and critique with that of engagement and practice. This Seventh Congress in Thimphu brought together scholars, practitioners and students of Himalayan, East Asian and South Asian healing systems, as well as social entrepreneurs, civil servants, and representatives of global businesses engaged in the commercial sale of Asia-derived medicinal products. This mélange of perspectives owed a lot to the theme of this Congress: Cultivating Traditions and the Challenges of Globalization.

\section{Cultivating the wilds}

In the context of the Seventh Congress of IASTAM, we co-organised a large multi-day panel titled 'Cultivating the Wilds: Considering Potency, Protection, and Profit in the Sustainable Use of Himalayan and Tibetan Materia Medica'. This panel included presenters who were from, or who had done extensive work in, Nepal, Bhutan, Ladakh, India, China (Tibet Autonomous Region and Yunnan, Sichuan, and Qinghai Provinces), and at sites of Tibetan medical production and practice in Europe. In this panel, we aimed to integrate knowledge, methods, and field experience from a variety of disciplines 
and professional perspectives to explore the intersection of conservation and development agendas related to Asian materia medica. A selection of the presentations given in Bhutan has been further developed for inclusion in this special issue of Asian Medicine.

We began our discussions in Thimphu with the assumption that the landscape of Asian medical production is undergoing a profound set of changes at present. Medicinal and aromatic plants are being increasingly commodified, and represent significant cultural and economic value to a range of stakeholders in new and increasingly interconnected ways. These changes are impacting the lives and work of am chi or sman pa (practitioners of gso ba rig pa, or the 'science of healing' in Tibetan $)^{1}$ in a range of contexts and locales, to village farmers, herb traders and middlemen, pharmaceutical factory directors and marketing specialists and scientific researchers as well as patients and consumers in many different countries. Medicinal plants represent not only pathways to healing but also to profit; they remain paragons of 'traditional culture' even as they are clinically tested for safety, quality, and efficacy according to biomedical and techno-scientific parameters. The various medicinal products derived from Himalayan and Tibetan raw materials are stable in one sensebased, as they are, on centuries of oral and textual tradition. Yet, like any aspect of culture, such products are also malleable, diverse, and at times embodiments of secret, guarded knowledge. Who holds or owns what knowledge, how it is passed down and to whom and for what ends are all questions we grappled with during the conference. In addition, we discussed the design and implementation of complex governance and regulatory structures related to the sourcing of medicinals and the production of medicines and other 'natural' products in Asian countries and beyond. Our collective voices raised important questions about what 'conservation' and 'sustainability' mean and what these concepts accomplish, both discursively and in practice. Himalayan and Tibetan materia medica exist at the intersections of local, regional and transnational regimes of value and within different economic and cultural frames: from the moral economy associated with the ethics of gso ba rig pa to the market economy which shapes worlds at local and global levels and which is implicated in practices of conservation and sustainability.

In relation to this theme of 'sustainability', the panel took up issues of overharvesting and the depletion of medicinal resources upon which Tibetan medicine and other Asian medicines depend. Market forces and the need for cash

\footnotetext{
${ }^{1}$ Other commonly used spellings for the previous three Tibetan terms are amchi, menpa, and Sowa Rigpa. Throughout this essay we use Wylie transliterations for Tibetan terms, except for personal names where we use the spellings preferred by subjects themselves.
} 
income at local and regional levels are giving rise to new challenges with respect to the use and availability of these materia medica. Concomitantly, there has been an increase over the past decade in cultivation efforts, research into substitutions (tshabs) for rare, endangered or otherwise unavailable ingredients, and a deepening desire to document and more clearly understand patterns of medicinal plant resource use across the region. As we heard from some panelists-Pei Shengji from the Kunming Institute of Botany and Amchi Gyatso Bista, the chairman of the Himalayan Amchi Association in Nepal, Tsewang Gombo, the project supervisor for the Ladakh Society for Traditional Medicine (LSTM), Ma Jianzhong and Samdrup Tsering of the Deqin Tibetan Medicine Research Association in Northwest Yunnan Province, China, and Ugyen Dorje, from the Ministry of Health in Bhutan-medicinal plant cultivation trials are ongoing and increasing in scope, with financial and technical support from governments and non-governmental organisations alike. In addition, efforts to create or expand protected areas and to monitor resource use are giving rise to new possibilities for collaboration between local communities, medical practitioners, scientific researchers, governmental and nongovernmental organisations and (social) entrepreneurs.

However, as crucial as such efforts are, these moves toward cultivation, conservation, and delimiting sustainable harvesting levels raise a host of challenges with respect to how to steward land and how to balance cultural and ecological possibilities and constraints with market-based concerns. Most of the Tibetan medical practitioners and conservation-development experts who presented preliminary results of cultivation trials pointed out that while certain species (such as ma nu, ru rta, and lcum rtsa) did quite well as cultivars, many trial plant species failed to germinate under these changed growing conditions. Often, the potency (nus $p a$ ) in Tibetan medical terms was considerably weaker in cultivated varieties than in wild-crafted specimens. In his presentation, Ed Smith, the founder and director of HerbPharm based in the United States, stressed the practical difficulties, time commitment, and technological resources that successful cultivation entails. Carroll Dunham, a social entrepreneur and the founder of Wild Earth, a Kathmandu-based herbal products company committed to sustainable sourcing and income generation, cited another practical limitation of cultivation: namely, the glutting of markets with plants that are relatively easy to cultivate and that are 'key' species for commercial production, such as Swertia spp. (tig talrgya tig), but that might throw other local agricultural systems and regional economies into cycles of rapid and unpredictable change as a direct result of commodification. Calum Blaikie echoed this concern, based on his long-term fieldwork among Ladakhi am chi. Daniel Winkler's longitudinal research on the (in)famous caterpillar 
fungus (Ophiocordyceps sinensis) across the greater Tibetan Plateau tells a compelling story about sustainability and the power of the market-through informal and formal economic channels - as a driver of human-environment interactions.

The methods by which quality and efficacy of cultivated and wild-crafted medicinal ingredients are determined can raise significant points of scientific and cultural incommensurability. Likewise, debates about the proper classification of medicinal plants and other materia medica across cultural and scientific systems — between Tibetan pharmacology and botany, for instance—expose concerns at once taxonomic and epistemological. Dr Dawa, the former director of the Men-Tsee-Khang in Dharamsala, India, and a leading expert in Tibetan medicinal plants, made important points in this regard during his presentation in Thimphu - points echoed in his more extensive Tibetan language essay which we have translated and include in this special issue. ${ }^{2}$ Kalden Nyima of the Lhasa-based Project to Strengthen Traditional Tibetan Medicine (PSTTM) raised similar concerns in his Thimphu presentation, and reiterates them in his practitioner's report, included herein. Kalden Nyima's father, Gawai Dorje, the renowned Tibetan medical practitioner and author of the Pure Crystal Mirror of Medicinal Plants ('Khrungs dpe dri med shel gyi me long) did not attend the conference in Bhutan. However, we have chosen to include an English translation of one of his original essays on the challenges of translating names of Tibetan materia medica into other languages. The combination of these three papers in translation represent a wealth of knowledge from foremost Tibetan medical experts in both India and China—scholarship that has not been easy for non-Tibetan scholars to access and that all too often has not been put in direct dialogue with each other, even in Tibetan language.

Other presentations given in Bhutan dealt directly with trade, commodification, and regimes of governance connected to the ways medicinal plants are used in contemporary contexts, in Himalayan and Tibetan milieu and globally. The equitable distribution of resources and determination of 'ownership' of traditional knowledge in this context raise further legal, cultural, and political issues. Such concerns were elucidated by Chamu Kuppuswamy in her presentation and further developed in her paper on Intellectual Property Rights (IPR) and Traditional Knowledge (TK). In his conference presentation and the practitioner's report included in this issue, Herbert Schwabl discussed the blessings and burdens of 'tradition' with respect to the production and sale of Tibetan medicines in modern European contexts. Schwabl is a senior rep-

2 Tibetan versions of these essays are available through the IASTAM website: http://www. iastam.org. 
resentative of Padma, Inc., the only company that currently produces and sells Tibetan medicinal formulas in Switzerland and Austria, with permissions for distribution in the United Kingdom pending. In his report, Schwabl discusses the ways 'traditional medicines' operate as discursive categories within the context of state regulation of all medicines, and as commodities within the greater context of increasing market-based activities around 'complementary and alternative medicines' (CAM) worldwide. In a similar vein, Mona Schrempf put forth a preliminary interdisciplinary research agenda on the globalisation of 'traditional' Chinese and Tibetan medicines. This agenda encourages comparative analyses of how several hallmark Chinese and Tibetan pharmaceuticals whose ingredients stem from the Tibetan Plateau become recontextualised as both globalised and localised carriers of 'traditional' and 'modern' sentiment, often simultaneously. Furthermore, this dual sense of authenticity often emerges in strange consort with efforts at standardisation on the one hand and claims to extra-pharmacological efficacy (through ritual blessings, ideas of Tibetanness, etc.) on the other. Martin Saxer, whose paper is included in this volume, presented a fascinating study of Himalayan border regimes, at once geopolitical and ideological, which are impacting the trade of medicinal plants between Nepal and China. In his treatment of this issue, we see how supposedly 'fixed' practices of licensing and certification, tests for drug quality, etc. come up against social and economic realities that demand flexibility and innovation at all points along this trade route, at once ancient and (post)modern.

Finally, impacts of climate change on high altitude medicinal plants can neither be underestimated nor easily assessed in the context of the 'third pole': Himalayan and Tibetan mountain environments. Jan Salick, a leading ethnobotanist of high Asia based at the Missouri Botanical Gardens, posed difficult yet crucial questions about the purpose of cultivation in the first instance. She stressed that cultivation should not be viewed unproblematically as a pathway to biodiversity conservation; rather, she argued that cultivation should be seen as fundamentally linked to world economic systems and market-based activities involving medicinal plants. In other words, cultivation should not be seen as a panacea for protecting vulnerable high altitude species, including those such as the snow lotus (Saussurea medusa, bya rgod sug pa), which she and colleagues in Yunnan have studied intensively. For Salick, cultivation is fundamentally untenable because the resources in question cannot be scaled up. Yet how to reconcile this with the general thrust of the commodification of Tibetan medicine, and its powerful and pervasive link to notions of cultural preservation as well as the commodification of Tibetan cultural concepts more generally, proves especially challenging today. Salick 
also inserted into the discussion the role that global climate change is playing not only within Himalayan and Tibetan natural ecologies, but also social ecologies - changes that bear on how Tibetan medical practitioners harvest plants, make medicines, and treat patients. These issues also play out through dynamics between national park and protected area managers and the people who make their homes or have historically used resources from these environments. The creation of protected areas introduces additional variables into efforts to define, promote, or monitor 'sustainable' use of medicinals.

All of these concerns point toward the intersection of cultural integrity, environmental protection, different ways of knowing and interacting with the world, and the socioeconomic pressures that are concomitant with modern life. They also present unique opportunities for cross-disciplinary and crosscultural engagement. Of the many themes to emerge from the conference and which are threaded through the papers included in this special issue, three emerge as central. First is the relationship between conservation, preservation and sustainability. Second is the sense that medicinal plants are what our colleague Laurent Pordié (2002) has called 'biocultural objects'. And third is the centrality of translation, both as key metaphor for work on Himalayan and Tibetan medicinal plants, and as a practical act. These three themes are deeply intertwined, but we find it useful to stream out some key components of each, below.

\section{Conservation, preservation and sustainability}

The concepts of conservation and sustainability have taken on widespread, global currency over the past two decades. However, the roots of these ideas can be traced to specific political and economic processes that converged at a particular historical moment. While a general concept of 'conservation' may not be the sole product of Euro-American ideas and historical processes, there is a conceptual lineage between contemporary discussions of conservation, preservation, and sustainability and the development of these ideas in Europe and North America. We find it useful to briefly outline the history of 'conservation' in the Euro-American context in order to explore the connections between and ramifications of past histories in the current moment.

Stemming from romanticist reactions first to the Enlightenment and then to the Industrial Revolution in the eighteenth century, a sensibility of valuing 'nature' and 'wilderness' as embodying intrinsic worth-especially in contrast to rationalised and mechanised human artifices - developed in Euro-American intellectual and popular circles. In the United States in the nineteenth century, such views became popularised in the well-known works of Ralph Waldo 
Emerson and Henry David Thoreau. Somewhat later, John Muir emerged as one of the leading voices of proto-environmentalism and what we might call a preservationist ethic, espousing the concept of wilderness preservation areas — where human presence and activity would be severely curtailed — and founding one of the oldest environmental organisations in the United States, The Sierra Club. Muir's idea pivoted around the notion that 'wilderness' was in and of itself valuable, regardless of utility. This would in part, during Muir's time as well as after, take the form of the establishment of national parks, protected areas and nature reserves. In the United States, for example, Yellowstone National Park was established in 1872 with the expressed view that this was an area worthy of protection:

[This] tract of land... is hereby reserved and withdrawn from settlement, occupancy, or sale under the laws of the United States, and dedicated and set apart as a public park or pleasuring ground for the benefit and enjoyment of the people...

Yellowstone was one of the first national parks established in the Western Hemisphere and would in many ways become a key model for national parks and preservation/conservation areas worldwide. ${ }^{4}$ In 1948, the International Union for the Protection of Nature (later known as the IUCN and later still as the World Conservation Union but maintaining the acronym IUCN) was founded with the stated goal of 'the preservation of the entire world biotic environment'. 5 This was perhaps one of the earliest examples of governmental and non-governmental organisations collaborating in the area of preservation/ conservation on an international level; such collaboration is also reflected in several of the articles contained within this issue. It should be noted that the IUCN is currently responsible for establishing and maintaining a list of threatened species, termed the Red List, which is used globally to decide the endangerment status of species, and to which many of our panelists refer, directly or indirectly, in their work.

Running parallel to these preservationist views of landscape, ecology and biodiversity was a movement that sought to combine the sensibility of an appreciation for 'nature' with a conviction that 'nature' is primarily an assortment of resources that should and need to be utilised-but with ever so much care, with (the ideology and empirical practice of) science as a powerful guide, and with the state as protector/enforcer of resource use conservation policies.

3 Chittenden 1915 , pp. 77-8. Note here the complete disregard for people already living within the area that became the park, such as Native Americans. We will return to this point below.

${ }^{4}$ Nash 2001; Igoe 2003; Trusty 2010.

5 Quoted in Nash 2001, p. 361. 
Throughout Europe this initially took the form of forestry science with special focus on sustainable-yield management. ${ }^{6} \mathrm{~A}$ fundamental premise of this movement was that national governments would ensure 'sustainable' harvesting according to newly formed social and scientific metrics. As with other aspects of European colonial-era administrations, many of these same techniques of resource management were applied in the colonies, particularly in Africa, and South and Southeast Asia-including the region of concern for this volume, the Himalayas. Agrawal discusses the work of Dietrich Brandis in Burma in the mid-1800s, where the 'linear evaluation survey' method was utilised to maintain the 'model forest' - a kind of ideal forest in which supposed perfect equilibrium exists due to careful calculation and harvesting annual increments only. ${ }^{7}$ As Agrawal quips about this kind of forestry, 'Numbers came to shape the way the world of trees and vegetation would be regarded and understood'. 8

Under colonialism, when utility was considered and factored in, as was the case with the concept of conservation of forests, it was quite narrowly defined by colonists as useful to the empire. Hence Agrawal discusses the centrality of teak in Burma as being important for British Naval ambitions and therefore being the focus of conservation efforts by Brandis. Non-imperial uses, such as for local subsistence, were continually seen as problematic to the goal of conservation during the colonial era. ${ }^{9}$ We might extend this argument today, and suggest that utility is in effect defined by international organisations and national governments in terms of being useful to the global economy and more specifically the markets for 'sustainably sourced' 'natural' medical products from the greater Himalayas. Many of the founding ideas of conservation and sustainable development implicit in forestry management of the colonists remained in place in post-colonial administrations (including in many areas of the Himalayas), as Nash (2001), Igoe (2003), and West (2006), among others, discuss.

Even today, while numbers do not completely determine the ways medicinal plants are regarded, they nonetheless remain an important element in the discourses of conservation, preservation, and sustainability in Himalayan and Tibetan contexts. Certainly the concept of sustainability, based on the notion of sustainable yield as a particular, quantifiable measurement, is quite central

\footnotetext{
${ }^{6}$ Scott 1998; Guha 2000; Agrawal 2005; Nash 2001.

Agrawal 2005, pp. 39-43. Incidentally, this became the model for forestry management in the United States, as reflected in the work of Gifford Pinchot, the first head of the US Forest Service.

${ }^{8}$ Agrawal 2005, p. 37.

${ }_{9}$ Agrawal 2005, pp. 32-64.
} 
to much state and non-governmental conservation initiatives in the region. In the Himalayas as elsewhere, concepts of conservation and sustainability also have become quite directly, if paradoxically, coupled with ideas of 'development'. By this logic, economic growth and improved livelihoods are also supposed to facilitate the conservation of natural resources and Earth's biodiversity. Yet as many of the papers in this volume illustrate, it is quite difficult to square concepts of 'sustainability' with efforts to scale up the Tibetan medical industry, either from the perspective of commodification and sheer resource use or from the perspective of a moral economy of gso ba rig pa practice and the standards of medicinal potency and benefit that practitioners of this tradition espouse.

Turning again towards history, the national park model of preservation came under fire in the last decades of the twentieth century. As discussed above, most national parks were quite exclusionary of people except as temporary (non-residential) consumers of natural beauty. This model encountered resistance among a large portion of the world's populace that was already living within the claimed boundaries of national parks. ${ }^{10}$ In some cases, alternative models were put forth, many of them in the Himalayas. One of the first of these was the Annapurna Conservation Area Project (ACAP) of Nepal, established in 1992. ACAP was a newly conceptualised category of Protected Area (defined by IUCN) that aimed to explicitly link human dwelling in particular environments, their histories of environmental stewardship in these contexts, and their contemporary livelihood needs with the goals of conservation. The idea of joint conservation-development projects (and related concepts such as eco-tourism) was fleshed out, in great part, through initiatives such as ACAP. Today, ACAP is Nepal's largest protected area, measuring $7629 \mathrm{~km}^{2}$; total coverage for protected areas in Nepal is currently $34,000 \mathrm{~km}^{2}$, according to the official governmental website of the National Parks of Nepal. ${ }^{11}$ In Ladakh (the location of Blaikie's work), protected areas cover $15,000 \mathrm{~km}^{2}{ }^{12}$ in all of India nearly $157,000 \mathrm{~km}^{2}$ of land is under protected area status. In the Himalayan areas of China, dozens of protected areas exist, including the Baima-Meili Xueshan National Nature Reserve, where the work of Ma Jianzhong in this volume is located; this reserve is included within the larger Three Parallel Rivers UNESCO World Heritage Site (declared in 2003), approximately $9,390 \mathrm{~km}^{2} .{ }^{13}$

10 Igoe 2003.

11 www.dnpwc.gov.np.

12 Goeury 2010, p. 109.

13 How much environmental protection any of these designated 'protected areas' (or World Heritage sites) confer is an interesting issue, but one that is beyond the scope of this essay. Our 
While it is difficult to know how much overlap there is between these protected areas of conservation and actual sites of harvesting of medicinals, the mere presence of these zones of protection and conservation in the Himalayas signals a significant orientation at both the national and international levels to themes of conservation, preservation, sustainability. In this special edition, we witness Pei Shengji and colleagues propose that a number of significant areas within China for Tibetan medicinal plants should be designated for protection under the Important Medicinal Plant Areas scheme. Hence we can see the continuation of conceptual categories of conservation/preservation in the early twenty-first century, with newly created groupings focused on specific uses of natural resources. Furthermore, the value of these sites of conservationas spaces of 'wilderness' particularly for national and international tourists and other consumers of nature and 'traditional' culture-becomes augmented in a larger field of political-economic relations. As Nash states,

Thinking of wild nature as an actively traded commodity in an international market clarifies appreciation and largely explains the world nature protection movement. The export-import relationship underscores the irony inherent in the fact that the civilizing process, which imperils wild nature, is precisely that which creates the need for it. ${ }^{14}$

International donors, non-governmental organisations, and governmental agencies involved in conservation efforts all value 'the wilds' so represented in and by these protected areas.

Likewise, purveyors of knowledge about these landscapes, especially those who have specific expertise in natural resources with cultural and economic value-medicinal plants_-become crucial 'stakeholders' within the politics of conservation. Enter the Himalayan am chi, the Tibetan medical practitioner. Such people are increasingly being recruited to do the work of conservation and sustainability science. ${ }^{15}$ They are engaged in the transformation and interpretation of these concepts on the ground in strategic ways, for a range of reasons, as Calum Blaikie examines in his article with am chi in Ladakh. Gso ba rig pa practitioners' involvement in participatory species mapping projects such as those described herein by Ma Jianzhong, for example, can become an avenue for the recognition of specific types of indigenous/traditional knowledge-themselves key currency in efforts of such practitioners to defend

point here is to highlight the extent to which 'protection' and 'conservation' have entered into the discourses of state-making, (inter)national funding, and even subject formation of people like am chi and sman $p a$.

14 Nash 2001, p. 343.

15 Cf. Lama et al. 2001; Ghimere et al. 2005. 
and transform their medical praxis in a contemporary context- - to 'develop' am chi medicine, as many of our panel participants and interlocutors describe. ${ }^{16}$ Plant cultivation and efforts to broker wholesale trade in materia medica can provide reliable sources of income and extend local socioeconomic networks of $a m c h i$, but can also create or exacerbate divisions between $a m c h i$, as we see in Blaikie's paper.

For Tibetan medicine practitioners and many others, sustainability as a concept and joint conservation-development projects as lived practices become increasingly important avenues through which populations are governed-a process that Arun Agrawal (2005) has aptly dubbed 'environmentality', after Michel Foucault's 'governmentality'. Agrawal explores this occurrence in an area of the Himalayas of northern India and argues that a yoking between the state and local populations - often in consort with international NGOs-has created a new form of governance of natural resources as well the emergence of what he terms 'environmental subjects', people who are concerned about the environment and for whom the environment is an important domain of both cognition and action. ${ }^{17}$ This has clearly happened in many places, perhaps particularly so in some of the 'hot spots' of biological (and often cultural) diversity, from the highlands of Papua New Guinea ${ }^{18}$ to the jungles of Mexico ${ }^{19}$ to the Indonesian archipelago ${ }^{20}$ and, of course, the Himalayas, where protected areas exist and where funding for conservation efforts is intense and intensely sought after, as discussed in Blaikie's article in this issue.

As the wave of sustainability studies was starting to crest, Donald Worster and others noted that the notion of 'sustainable development' (and kindred ideas) is essentially an economic model applied to an extremely complex and unpredictable reality. ${ }^{21}$ Recall the forest departments of Europe and the United States and their proposals to keep the resources of the forest available for an indefinite amount of time: the economic viability of the forest needed to be maintained through careful calculations of sustainable yield. As it turns out, the 'model forest' on which sustainable yield was figured resembled no forests that actually exist. As Worster argues, a main problem with an equilibriumbased, economic model of 'sustainability' is how exactly to determine the parameters of environmental 'stress' and/or 'collapse'. Ecologists do not even agree on this. In part, Worster argues that this is due to the fact that previous

${ }^{16}$ Cf. Pordié 2008; Craig and Bista 2005.

17 Agrawal 2005, pp. 164-5.

18 West 2006.

${ }^{19}$ Hayden 2003.

${ }^{20}$ Lowe 2006.

${ }^{21}$ Worster 1993, pp. 142-55. 
notions of 'equilibrium' in nature are illusions. The environment is constantly in flux. ${ }^{22}$ Worster's warning to us from over a decade ago is one that we should pay careful attention to, especially since so much of our attention with respect to Himalayan medicinal plants does indeed seem to hinge very much on notions of utility on the one hand and preservation (both cultural and natural) on the other. Yet plants are more than commodities - if they are even that.

\section{Medicinal plants at biocultural objects}

Due to their fundamental utility as well as their symbolic and market values, medicinal plants are situated within social and cultural fields of activity and knowledge. Whether the plants are harvested from 'wild' sources or are cultivated intentionally, their existence intersects significantly with that of humanity. From one perspective, many medicinal plants are chemically active due to evolutionary forces that have helped maintain protection from predatorsincluding humans (since plants cannot flee from predators). Hence a 'medicine' within plants can also be a poison, as many an investigator of plant pharmacology has discovered throughout history. Humans have developed significant traditions of knowledge related to these medicinal/poisonous aspects of plants, undoubtedly aided through careful observation of other species' interactions with plants, as discussed in Dr Dawa's article in this issue. On the other hand, some plants may in fact 'benefit' from close interaction with 'predatory' humans-especially plants that are deemed 'useful' by human beings. A human community may in fact aid in the propagation and continuation of a plant community. Hence the 'poisons' that plants emit to protect themselves may prove to be valued by people, which may in fact prompt people to encourage the continued growth of that type of plant, which then also benefits the survival of the plant species.

The central trope of utility is in many ways at the heart of the themes that this special issue addresses. Plants utilised for medicine become objects (or perhaps participants) in networks of exchange, governmental regulations, related systems of material and information transfer, and physiological processes taking place within human bodies. It is their usefulness within localised and increasingly globalised/globalising contexts that links particular natural kinds with spheres of human activity in particular and powerful ways. Yet,

22 Worster feels there are other issues with sustainable development as well, including its strictly utilitarian orientation that ignores intrinsic value and non-utilitarian aspects of the environment. In this sense, his work resonates with that of John Muir's and the more general preservationist-oriented view of the wilds. 
how does this generalised utility relate to more specific notions of value, most germane in discussions of exchange, and in the points of tension that arise between localised barter economies or even moral economies tied to gso ba rig $p a$ ethics, and the logic of the market? More precisely, is an abstract notion of utility sufficient to understand the particular ways in which plants are valued within specific human fields of activity? Furthermore, what happens when there are varying values attached to plants by different human communities or actors and these, then, come into contact or conflict through systems of exchange?

Pordié has argued that plants are themselves expressions of culture. ${ }^{23}$ They are, in this sense, biocultural. Plants, especially medicinal ones that are grounded in particular systems of etiology, diagnosis, and consumption, are not just floating signifiers, even if they can be anchored to an 'objective' reality of the biological species, for example. An effective analysis of plants as biocultural kinds must then address the culturally relevant significations of plants. ${ }^{24}$ Pordié goes on to discuss the connections between plants, medical practice and practitioners, and the Buddhist religious tradition of Ladakh, where he has worked for many years, to argue that a plant can be seen as 'a principal vector of the symbolic efficacy of treatment'. ${ }^{25}$ Plants are endowed with medicinal power in part through ritual practices of am chi, wherein various aspects of cultural and religious life are infused into the 'object' of the plant or into compounded medicines. ${ }^{26}$ In this sense, one could argue that plants in the medical context embody certain kinds of power and force. This is in part reflected linguistically in Tibetan concepts of plants. In Tibetan, there are several words for the general term 'plant' in the medical context: the neologism rtsi shing and the more literary term of skye dngos ('things that grow'). ${ }^{27}$ The second term, at least, seems to imply some level of self-propulsion, some amount of agency and potentiality; a plant can become, in some sense, although not without the help of people, a culturally endowed object. We see this in part reflected in the significant arboreal metaphor of medical knowledge and learning in many Tibetan medical texts, and certainly in the medical paintings: medical knowledge can be represented by a tree-plant writ large.

\footnotetext{
23 Pordié 2002.

${ }^{24}$ Pordié uses the phrase 'biocultural objects' in his work (bioculturel objet), which links in compelling ways to ideas of commodification. However, we prefer the term 'biocultural kind' because this allows for inclusion of potentiality, as will be discussed below.

25 Pordié 2002, p. 186.

26 Craig 2010; Garrett 2009; Pordié 2008.

${ }^{27}$ Glover 2005. Here we exclude more specific terms such as sngo or sngo ldum (herbaceous plant) and shing (woody plant).
} 
At the same time as plants take on cultural meanings, they circulate in systems of exchange that have undoubtedly gone beyond localised pockets of culture for a very long time, as Saxer's contribution points out. Sometimes the culturally imbued plant is 'reborn' in a new locality; the cultural meanings associated with the plant may change. However, sometimes a consistency of meaning across cultural boundaries is retained-or at least put to use (and here we are back at utility again). This is possibly due to cultural borrowings, but is in part also likely due to some of the biochemical bases of healing properties in plants. These biochemical properties can become highly valued characteristics of plants, which can ultimately affect the harvesting and overall availability of the plant in any given region. Of course other social and cultural factors can affect the 'popularity' of a plant across cultural boundaries, some of which may be traceable to chemistry but some of which may be part of broader sociocultural systems of signification and value, couched within particular geopolitical milieu; witness the popularity of Ophiocordyceps sinensis in China as an aphrodisiac, as Winkler describes. Some of this plant popularity may be traceable to chemical properties but certainly much is also related to notions of fertility and sexuality, gender relations, conspicuous consumption, and effective marketing.

Whatever the possible roots of interest in utilisation of particular plants as medicines, we have without a doubt seen some significant changes in procurement, production, and marketing of materia medica within the greater Himalayan region within the past decade. In general, we identify these trends in terms of commodification, which we understand in Marxist politicaleconomic terms to involve the assignation of economic value to something that had not previously been understood, at least exclusively, in those terms. This is true even as discourses and practices of conservation, preservation, and sustainability are invoked. We have seen an increase in the amount of organisations, researchers, state-based and international structures of governance at work in this area to monitor, report, and propose solutions to issues of sustainability, as well as to regulate the ways medicinal plants and other materia med$i c a$ are traded and put to use in, or as, commercial products. Interestingly these pressures come both from the side of conservation and sustainability through national and international policies on rare and endangered species (in the form of CITES or the IUCN Red List, for example ${ }^{28}$ ), practitioners' own lists of threatened, rare, or expensive ingredients, etc., and from the more

${ }_{28}$ The Convention on International Trade in Endangered Species (CITES) is an international agreement between governments which aims to ensure that the global trade in wild flora and fauna does not threaten their survival. The International Union for the Conservation of Nature (IUCN) maintains a Red List of threatened species (see http://www.iucnredlist.org/). 
overtly market-implicated and techno-scientific demands of Good Agricultural Practices (GAP), Good Manufacturing Practices (GMP) and various other parameters for determining the 'quality' and 'safety' of drugs. ${ }^{29}$

It is interesting to note that, when spoken about in Tibetan, the transformation of goods or services into substances for which particular market-based values are assigned becomes inflected with a certain kind of morality. There is an explicit desire to retain some sort of cultural space that is not about money but that is about the provision of 'benefit' (phan) to sentient beings and the 'real' or 'authentic' (dngos nas) nature of this medical and cultural tradition. Of course this does not mean that the practitioners of Tibetan medicine with whom we engaged in Bhutan or whose work is represented here argue against commodification. Indeed, many are directly engaged in the act of 'scaling up' the Tibetan medical industry, in different ways-from Schwabl's work to bring Tibetan formulas to new European markets, to the 'elite' Ladakhi am chi about whom Blaikie writes, and the general if controversial trend amongst many contemporary Tibetan medical practitioners, in both rural and urban settings, to buy ready-made Tibetan pills and powders, as opposed to producing their own medicines. Yet do these changed production regimes mean the same thing in different social contexts?

In thinking about medicinal plants as biocultural kinds and linking this idea to the dual pressures to both conserve and commodify, we find resonance with Arjun Appadurai's concept of the 'social life of things', and to ideas about differential relations of exchange that this concept invokes. ${ }^{30}$ In his introduction to his book, The Social Life of Things, Appadurai writes, 'Focusing on things that are exchanged, rather than simply on the forms or functions of exchange, makes it possible to argue that what creates the link between exchange and value is politics, construed broadly. This argument... justifies the conceit that commodities, like persons, have social lives'. ${ }^{31}$ This focus on things is crucial for our purposes because it is these things-medicinal plants and other materia medica - that actually give rise to a certain kind of politics, as well as policies, on both ends of the conservation-commodification spectrum.

Many of the papers in this volume speak to the ways plants are at once biocultural objects and embodiments of socioeconomic, historical and political relationships. We point out the historical continuity of trade in medicinals throughout the greater Tibetan-Himalayan region as an example. Yet we also note the ways in which these patterns of exchange are now implicated in global

\footnotetext{
29 Saxer 2010, this issue; Craig 2006, 2010.

30 Appadurai 1988.

31 Appadurai 1988, p. 3.
} 
commerce, and how this changes the terms of this exchange at distinctly local levels. While the more abstract or globalised argument about 'trade' connected to cultivating medicinal plants as supposedly a way to offset industry growth (parallel to 'cap and trade' arguments in larger environmental debates) is of dubious legitimacy, ideas that link local or regional income generation to plant cultivation may be viable at some level. However, as is reflected in several papers included herein, and in recordings of our Thimphu discussions, ${ }^{32}$ this depends greatly on the vagaries of market forces and on the enactment and enforcement of regulations on the ground.

\section{The many meanings of 'translation'}

A third central theme to emerge from the conference and this special volume of Asian Medicine revolves around concepts and practices of 'translation'. We have already seen reference to this in the sections above, but it seems necessary to further elaborate what we mean. By translation, we refer not only to the multiple languages at play during our gathering in Bhutan, and the formal and informal moments of interpretation that defined our time together and made this cacophony of voices comprehensible, but also the layers of meaning and epistemological complexity that communication entails. Translation, in this sense, relates to the intersection of different knowledge systems and places on the map. Acts of translation can bridge distances between abstract and inadequate dichotomies such as local/global or tradition/modernity. Good translation can help to create a continuum and a dialogue where there might otherwise be only silence or the assumption of difference. Consider the words of the Spanish philosopher, José Ortega y Gasset.

The stupendous reality is that language cannot be understood unless we begin by observing that speech consists above all in silences. A being who could not renounce saying many things would be incapable of speaking. And each language represents a different equation between manifestations and silences. Each people leaves some things unsaid in order to be able to say others. Because everything would be unsayable. Hence, the immense difficulty of translation: translation is a matter of saying in a language precisely what that language tends to pass over in silence. $^{33}$

Following Ortega, we understand translation to be a process of distillation wherein decisions are made about what details are most important to repre-

32 Podcasts of the talks are available at www.iastam.org/conferences_VII_podcasts.htm.

33 Ortega y Gasset, quoted in Becker 1995, p. 6. 
sent, what might be taken for granted, and how to reconcile the spaces in between.

While in Bhutan, each of us endeavoured to stretch beyond linguistic and disciplinary 'comfort zones' so that we might make the most of this extraordinary meeting and the opportunities it afforded. Presenters on our panel included native speakers of Nepali, Dzongkha, German, Chinese, English, and various dialects of Tibetan. The ability to speak with each other and share information depended on imperfect yet well-intentioned efforts on all of our parts to listen carefully, to ask questions, to speak slowly. While some nonnative English speakers choose to present in English, others requested the assistance of a translator.

Consider the following example. Sienna served as interpreter for one of our long-term colleagues Dr Gyatso Bista, an am chi from Mustang District, Nepal. This was not the first time these two individuals have stood side by side at a podium. However, in most other circumstances, Sienna has translated for Gyatso in front of an audience of non-Tibetan speakers. In this case, a testament to the uniqueness of this IASTAM event, the audience was as diverse as our array of panelists. As such, she found herself choosing words differently than in past moments. She knew that others in the audience could probably surpass her technical aptitude in Tibetan. And yet she was the right person for the job because of their shared vocabulary of experience: Sienna knew intimately the places of which Gyatso spoke, and the people with whom he was working. She could anticipate the arc of his discourse, having heard him speak on such topics in the past. In short, there were few silences between them. Yet the nature of instantaneous translation and the time constraints of a formal conference setting created other silences, elided other areas of comprehension. While Gyatso felt compelled to describe his home region and the different planting methods he had used for medicinal plant cultivation trials, Sienna felt more obliged to capture the particular idioms and metaphors with which this am chi discussed his experiences. In a different setting, Sienna might have glossed over Gyatso's comments about the particulars of Mustang's air and soil in relation to a plant's potency and the five elements ('byung ba lnga), aiming instead for a more overarching commentary about the ways materia medica are harvested and prepared in the gso ba rig pa tradition to people with little shared cultural context. And yet in this and other moments in Bhutan, while the words of a Tibetan speaker were interpreted in approximate English, the space created for reflection when patterns of speech are not monolingual became productive and meaningful.

Beyond world languages and challenges presented by the need for simultaneous translation, we also had disciplinary tongues to contend with: anthropology, ecology, ethnobotany, development, business, biomedicine, and law, 
as well as the overarching yet unevenly shared vocabulary of gso ba rig $p a$, the 'science of healing', its theoretical principles, historical background, and key metaphors. This diversity is retained in the essays included herein. Our discussion about the uses of medicinal plants and other materia medica not only involve acts of translation across language and discipline, but also across scientific, economic, and cultural value systems, as we have alluded to above. The essays of Blaikie and Saxer emerge from a strongly anthropological tradition, both in terms of the extensive fieldwork that undergirds their arguments and in terms of their analytical frames. For example, Blaikie encourages us to consider alternative meanings of the concept 'endangered species' through an analysis of contemporary am chi practice in Ladakh. His argument is an act of translation in that he asks us to reconsider the intense focus on Himalayan medicinal plants as sites of endangerment from the perspective of am chi themselves. How have particular kinds of am chi praxis become 'endangered' by virtue of the increased focus on conservation activities on the one hand and the increasing industrial production of gso ba rig $p$ a formulas on the other?

Other papers and presentations address the tricky work of translation across classificatory systems, as well as across the domains of descriptive studies of ecological change and of evaluative studies geared toward the more intervention-oriented agendas of conservation and development. The scholarship of Daniel Winkler, Pei Shengji, and Ma Jianzhong illustrate these dynamics. Each essay is informed by long-term in situ engagement with natural and social ecologies across the Himalaya and Tibetan Plateau. Their contributions translate across registers of ethno- and economic botany into the languages of conservation and development. Pei translates decades of work documenting medicinal plants across High Asia into rationales for the creation of new protected areas and reserves in China. Winkler tracks the freakonomics ${ }^{34}$ behind the yartsa gunbu phenomenon, putting the dynamic nature of rural household economies, cash-based and barter-oriented trade relationships, commodities markets, and official Chinese economic indices, into dialogue with each other-or at least translating the silences between them, when it comes to this unique and pervasive substance.

In the appendix we list different species that have been the subjects of cultivation trials. The inclusion of these Appendices is itself an effort to make more widely available disparate knowledge about which plants are being cultivated, how, where, to what end, and with what outcomes. Yet technical and cultural acts of translation abound, even in these seemingly straightforward lists. Consider the various names for materia medica across Tibetan, Sanskrit,

\footnotetext{
${ }^{34}$ Cf. Levett and Dubner 2005.
} 
Chinese, Latin, and common English, and the diverse epistemologies that underlie these names. Classification systems have long been seminal areas of inquiry for anthropology and ethnobotany/ethnobiology. ${ }^{35}$ Incommensurate classifications have given rise to much confusion when it has come to determining everything from sustainable harvesting levels to pharmacological substitutions (tshabs in Tibetan) for ingredients that are either not available or prohibitively expensive. ${ }^{36}$ As such, these species lists are enmeshed in crosscultural and multidisciplinary debates about provisioning correct Linnaean equivalents for Tibetan and Himalayan plants. Gawai Dorje's paper addresses exactly this. These species lists are also emblematic of debates about the names of things: from regional variations that surface in an effort to provide definitive contemporary examples of plants described in Tibetan medical texts or centuries-old drawings of medicinal plants as represented in sources like Desi Sangye Gyatso's Blue Beryl, ${ }^{37}$ to efforts to assign a correct biochemical profile to a particular plant based on laboratory science performed in contexts far removed from the sites in which such plants grow or are harvested and made into medicines.

The theme of translation across value systems can be elucidated also through a careful examination of key terms and how they move across sociolinguistic registers. What do words like 'sustainability' and 'conservation' mean when they are translated into Tibetan? How does the idea of trade-trade regulations, trade secrets, and industries - relate to culturally embedded systems of exchange or to more local and regional economies? How does a concept like 'commodification', which is so entangled in a net of cultural, historical, and political-economic relations, get unraveled in a foreign tongue? How does 'potency' translate across different scientific, disciplinary, and cultural registers?

Questions about how the concepts of sustainability and conservation, and the values associated with them, get translated and/or conveyed at local levels are compelling sites of inquiry. The discourses of conservation and sustainability have taken root in possibly new and significant ways among many of the world's populace, including gso ba rig pa practitioners and the communities that harvest, trade in, grow, or otherwise produce and consume Tibetan

35 Durkheim and Mauss 1963 [1903]; Berlin, Breedlove, and Raven 1973; Berlin 1992; Ellen and Reason 1979; Hunn 1975, 1976, 1982; Glover 2005.

36 Glover 2010; Boesi and Cardini 2006.

37 Desi Sangye Gyatso (1653-1705) was the regent of the 'Great' Fifth Dalai Lama and an accomplished scholar of gso ba rig pa. The Blue Beryl (Bai dur sngon po) and the eighty paintings that illustrate this medical treatise are among the most significant cultural and medical documents within the history of gso ba rig pa. 
medicine(s). Yet as powerful as official/international understandings of 'conservation' and 'sustainability' may be, these are not the only sites in which meaning is made or the pragmatic work of conscious resource use is undertaken. The Tibetan term that largely is used as an equivalent for 'conservation' is srung skyob, a combination of terms that means to protect, safeguard or defend; in fact, srung is the same term in Tibetan for amulet, a protective item that one usually wears around one's neck to keep harm at bay-particularly harm that can be inflicted by a whole range of nefarious spirits and other forces that dwell in particular places and distinct ways throughout the greater Tibetan landscape. ${ }^{38}$ The notion of utility does not seem to be a significant part of the Tibetan term.

What a linguistic analysis of the term srung skyob seems to indicate is that the Tibetan concept that often gets translated as 'conservation' is in some ways more akin to the idea of preservation, to relationships between different classes of sentient beings (human and non-human, animal and vegetal), and to an ethic of resource use that is at times quite intimately if also subtly linked with Buddhist ideals and concepts about 'right livelihood', 'right practice', and moral imperatives against greed. We see such notions expressed in the papers of Dr Dawa and Kalden Nyima. And, even if we clearly understand that these are ideals, it is still worth noting that this involves a very different conception of 'nature' and the meaning underlying concepts such as 'preservation' or 'conservation'. Notions of 'sustainability', by turns, translate in a range of ways in Tibetan language. There is no one equivalent word, at least not in how the concept is translated in practice. Discussions of sustainability in local vernaculars produce phrases such as 'using plants in the right way' or 'harvesting so there is enough in the future'. A perusal of the transcript from our panel reveals that at certain points and in strategic, if not always conscious ways, each of us chose to rely on English or Chinese instead of translating such terms, even when these terms were couched within a sentence that was otherwise spoken in another language. Intellectual Property Rights (IPR) is another example of this phenomenon.

Such moments exemplify Ortega y Gasset's insight that translation involves certain choices about what not to interpret. We would add that these choices are made in particular social and political-economic contexts and are often enmeshed in an array of power relations that can often render one interpretation more valid or reliable than others. What counts as evidence of good sourcing? What methods are used to determine the potency of a plant? These instances in which terms are not translated raise issues about what types of

${ }^{38}$ Cf. Samuel 1993. 
knowledge come to merit translation, however imperfect. Such moments also raise questions about equivalency and alignment. Does the Tibetan cognate phan nus_phan meaning 'benefit' and nus referring to 'potency'-really capture the meaning of 'efficacy', either with reference to its lay meaning, the capacity to produce a desired outcome, or in a more constrained biomedical sense of something that produces a specific, reproducible effect under controlled experimental conditions? Or, in another sense, does cultivating a few key species really translate into the alleviation of overharvesting pressures on wildcrafted plants? Can such acts of conservation (or industry-driven income generation, depending on how one looks at it) come to stand for 'sustainable harvesting' or 'green' business? Where do Buddhist concepts of 'right livelihood' fit into this picture? These and other questions remain open to debate, but we have been grateful for the opportunity to engage them, both in person and on the page.

\section{Honouring a friend}

A final yet crucial note is in order. The panel we organised in Thimphu was dedicated to Yeshi Chödren Lama (1971-2006). Yeshi was one of the 24 people who lost her life in the tragic helicopter crash in eastern Nepal in 2006, an event that also took the life of Mingma Norbu Sherpa and Chandra Gurung, leading conservationists and the original engineers of ACAP among many others. The crash was a huge loss for scores of people. When Sienna first met Yeshi in 1996, this young Tibetan woman had just returned from Middlebury College in Vermont. Yeshi joined the World Wildlife Fund Nepal Program in 1997, and immediately began working in Dolpo. What began for Yeshi as a project management assignment would quickly turn into a much deeper personal and professional commitment. Her scholarly contributions include a book on medicinal plants of Dolpo that she co-authored in 2001, collaborative articles with colleagues at WWF and the UNESCO People and Plants Initiative, and her MPhil thesis at SOAS in London. Her dedicated engagement with am chi, local villagers, government representatives, and international scholars and consultants, and of course her co-workers and supervisors at WWF, straddled high quality scholarship and engaged conservation and development work. Yeshi's background in anthropology and international studies, as well as her fluency in Tibetan, were huge assets in this process, and deeply appreciated by all the people she worked with in Dolpo, and later with the Himalayan Amchi Association, as well as her later work in the Kanchenjunga area. 
Yeshi bridged many worlds - worlds represented by all of us who gathered for this panel. She was as much a Tibetan as she was marked by her life in Nepal. She held fast to her family's history in Tibet and Bhutan even as she made her peace, like so many Tibetans do, with the experience of exile. She was a scholar in the truest sense of the term: inquisitive, skeptical, with a deeply collaborative spirit and a commitment to the exchange of knowledge across cultural and disciplinary borders. She was a practitioner, in all senses of this term: dedicated, filled with duty and devotion to the people with whom she worked. Many of us still mourn her death and strive to continue the work to which she was so committed. And so, this conference was a bittersweet moment for those who knew Yeshi and those who have benefited, directly or indirectly, from her lifework. We hope that the exchange of ideas and experiences presented in this special issue will continue to inspire us: to remind us of all we do not know and to keep us working with the spirit of collaboration, respect, and insight that Yeshi embodied.

\section{Acknowledgements}

We gratefully acknowledge support from a Weiss Family Faculty Research/ Conference Grant through the Nelson A. Rockefeller Center for Public Policy and Social Science, and a conference travel grant from the John S. Dickey Center for International Understanding, both at Dartmouth College. We also thank the Trace Foundation and the University of Puget Sound for their support. These grants made possible our panel at the IASTAM Bhutan conference. Additionally, we would like to thank Theresia Hofer for her assistance at every stage of the IASTAM event, and Tsering D. Gonkatsang for his meticulous and thoughtful translation of the three original Tibetan language essays.

\section{References}

Agrawal, A. 2005, Environmentality: Technologies of Government and the Making of Subjects, Durham: Duke University Press.

Appadurai, A. 1988, The Social Life of Things: Commodities in Cultural Perspective, Cambridge: Cambridge University Press.

Becker, H. 1995, 'Introduction,' In Beyond Translation: Essays toward a Modern Philology, Ann Arbor, MI: University of Michigan Press, 1-20.

Berlin, B., D. E. Breedlove, and P. H. Raven 1973, 'General Principles of Classification and Nomenclature in Folk Biology', American Anthropologist 75: 214-42.

Berlin, B. 1992, Ethnobiological Classification: Principles of Categorization of Plants and Animals in Traditional Societies, Princeton: Princeton University Press. 
Boesi, A. and F. Cardi 2006, 'Tibetan Herbal Medicine: Traditional Classification and Utilization of Natural Products in Tibetan Materia Medica', HerbalGram 71: 38-48.

Chittenden, H. M. 1915, The Yellowstone National Park-Historical Description, Cincinnati: Stewart and Kidd Co. www.archive.org/details/yellowstonenati02chitgoog (accessed 14 October 2010).

Craig, S. R. and G. Bista 2005, 'Himalayan Healers in Transition: Professionalization, Identity, and Conservation among practitioners of gso ba rig pa in Nepal', in Y. Thomas, M. Karki, K. Gurung, and D. Parajuli (eds), Himalayan Medicinal and Aromatic Plants: Balancing Use and Conservation, Kathmandu: WWF Nepal Program, 411-434.

Craig, S. R. 2006, On the Science of Healing: Efficacy and the Metamorphosis of Tibetan Medicine, PhD dissertation, Department of Anthropology, Cornell University, Ithaca, NY.

2010, 'From Empowerments to Power Calculations: Notes on Efficacy, Value, and Epistemology', in V. Adams, M. Schrempf, and S. Craig (eds), Medicine Between Science and Religion: Explorations on Tibetan Grounds, London and New York: Berghahn Books, 215-240.

Durkheim, É. and M. Mauss 1963 [1903]), Primitive Classification, Chicago: University of Chicago Press.

Ellen, R. F. and D. Reason (eds) 1979, Classifications in Their Social Context, San Francisco: Academic Press.

Garrett, F. 2009, 'The Alchemy of Accomplishing Medicine (sman sgrub): Situating the Yuthog Heart Essence Ritual Tradition', Journal of Indian Philosophy 37, 3: 207-30.

Ghimire, S. K., D. McKey, and Y. Aumeeruddy-Thomas 2005, 'Heterogeneity in Ethnoecological Knowledge and Management of Medicinal Plants in the Himalayas of Nepal: Implications for Conservation', Ecology and Society 9, 3: article 6.

Glover, D. M. 2005, Up From the Roots: Contextualizing Medicinal Plant Classifications of Tibetan Doctors in Rgyalthang, PRC, PhD dissertation, University of Washington.

_ 2010, 'Classes in the Classics: Historical Changes in Plant Classifications in Two Tibetan Medical Texts' in S. Craig, M. Tsomo, F. Garrett, and M. Schrempf (eds), Studies of Medical Pluralism in Tibetan History and Society, Bonn: International Institute for Tibetan and Buddhist Studies, Contributions to Research on Central Asia Series.

Goeury, D. 2010, 'Ladakh, Kingdom of Sustainable Development? Protecting the Natural Environment to Protect Identity', Journal of Alpine Research 98: 109-21.

Government of Nepal, Ministry of Forests and Soil Conservation, Department of National Parks and Wildlife Conservation, www.dnpwc.gov.np (accessed 14 October 2010).

Guha, R. 2000, Environmentalism: A Global History, Menlo Park, CA: Longman.

Hayden, C. 2003, When Nature Goes Public: The Making and Unmaking of Bioprospecting in Mexico, Princeton, NJ: Princeton University Press.

Hunn, E. 1975, 'A Measure of the Degree of Correspondence of Folk to Scientific Biological Classification', American Ethnologist 2, 2: 309-27.

_ 1976, 'Toward a Perceptual Model of Folk Biological Classification' American Ethnologist 3: $508-24$.

_ 1982, 'The Utilitarian Factor in Folk Biological Classification', American Anthropologist 84: 830-47.

Igoe, J. 2003, Conservation and Globalization: A Study of National Parks and Indigenous Communities from East Africa to South Dakota (Case Studies on Contemporary Issues), Wadsworth Publishing.

Lama, Y., S. Ghimire, and Y. Aumeeruddy-Thomas 2001, Medicinal Plants of Dolpo: Am chis Knowledge and Conservation, Kathmandu: WWF Nepal Program Publication Series.

Levett, S. and S. Dubner 2005, Freakonomics: A Rogue Economist Explores the Hidden Side of Everything, New York: Penguin Books.

Lowe, C. 2006, Wild Profusion: Biodiversity Conservation in an Indonesian Archipelago, Princeton, NJ: Princeton University Press. 
Nash, R. F. 2001, Wilderness and the American Mind, New Haven: Yale University Press.

Pordié, L. 2002, 'La pharmacopée comme expression de société: Une etude himalayenne', in Fleurentin, J., G. Mazars, and J. M. Pelt (eds), Des sources du savoir aux médicaments du futur, Paris: Editions IRD-SFE, 183-94.

2008, 'Reformulating Ingredients: Outlines of a Contemporary Ritual for the Consecration of Medicines in Ladakh', in M. van Beek and F. Pirie (eds) Modern Ladakh: Anthropological Perspectives on Continuity and Change, Leiden: Brill, 152-174.

Samuel, G. 1993, Civilized Shamans: Buddhism in Tibetan Societies, Kathmandu: Mandala Book Point.

Saxer, M. 2010, Manufacturing Tibetan Medicine: The Creation of an Industry and the Moral Economy of Tibetanness, PhD dissertation, University of Oxford.

Scott, J. C. 1998, Seeing Like a State: How Certain Schemes to Improve the Human Condition Have Failed, New Haven: Yale University Press.

Trusty, Teressa. 2010. The Politics of Representing Nature, Culture, and Conservation in Northwest Bolivia, PhD dissertation, University of Washington.

West, P. 2006, Conservation is our Government Now: The Politics of Ecology in Papua New Guinea, Durham, NC: Duke University Press.

Worster, D. 1993, The Wealth of Nature: Environmental History and the Ecological Imagination, New York: Oxford University Press. 